\title{
Development of GIS-based fuzzy pattern recognition model (modified DRASTIC model) for groundwater vulnerability to pollution assessment
}

\author{
J. Iqbal · A. K. Gorai · Y. B. Katpatal • \\ G. Pathak
}

Received: 3 September 2013/Revised: 5 August 2014/Accepted: 19 October 2014/Published online: 11 November 2014

(C) Islamic Azad University (IAU) 2014

\begin{abstract}
Groundwater is one of the main sources of drinking water in Ranchi district and hence its vulnerability assessment to delineate areas that are more susceptible to contamination is very important. In the present study, GISbased fuzzy pattern recognition model was demonstrated for groundwater vulnerability to pollution assessment. The model considers the seven hydrogeological factors [depth to water table $(D)$, net recharge $(R)$, aquifer media $(A)$, soil media $(S)$, topography $(T)$, impact of vadose zone $(I)$, and hydraulic conductivity $(C)$ ] that affect and control the groundwater contamination. The model was applied for groundwater vulnerability assessment in Ranchi district, Jharkhand, India and validated by the observed nitrate concentrations in groundwater in the study area. The performance of the developed model is compared to the standard DRASTIC model. It was observed that GIS-based fuzzy pattern recognition model have better performance than the standard DRASTIC model. Aquifer vulnerability maps produced in the present study can be used for environmental planning and predictive groundwater management. Further, a sensitivity analysis has been performed to evaluate the influence of single parameters on aquifer vulnerability index.
\end{abstract}

Keywords Groundwater vulnerability - Ranchi district . Fuzzy pattern - Optimization · Sensitivity analysis · GIS

\footnotetext{
J. Iqbal · A. K. Gorai $(\bowtie) \cdot$ G. Pathak

Environmental Science and Engineering Group, Birla Institute of

Technology Mesra, Ranchi 835215, Jharkhand, India

e-mail: amit_gorai@yahoo.co.uk

Y. B. Katpatal

Department of Civil Engineering, VNIT Nagpur,

Nagpur 440010, Maharashtra, India
}

\section{Introduction}

The concept of aquifer vulnerability to external pollution was introduced in 1968 by Margat, with several systems of aquifer vulnerability assessment developed in the following years (Voss 1984; Carsel et al. 1985; Al-Adamat et al. 2003; Dixon 2005; Gemitzi et al. 2006; Massone et al. 2010). The reason behind the different groundwater vulnerability to pollution zone is the variations in hydrogeological settings. The importance of groundwater vulnerability assessment arises from the fact that groundwater monitoring is time-consuming and too costly to adequately define the geographic extent of contamination at a regional scale. Thus, examination and identification of the spatial distribution of the various vulnerable areas to contamination is quite important. The vulnerability maps are useful tools for allocating limited monitoring resources to areas where they are most needed (Burkart and Feher 1996; Thapinta and Hudak 2003). The approaches developed to evaluate aquifer vulnerability include process-based methods, statistical methods, and overlay/index methods (Wagenet and Histon 1987; Leonard et al. 1987). Among all the methods, overlay and index method is widely used for vulnerability assessment. The overlay/index methods use location-specific vulnerability index based on the factors controlling movement of pollutants from the ground surface to the water-bearing strata. The DRASTIC model (Aller et al. 1987) is one of the most widely used overlay and index method to assess intrinsic groundwater vulnerability to contamination (Al-Adamat et al. 2003; Babiker et al. 2005; Tirkey et al. 2013; Shirazi et al. 2013). The DRASTIC method integrates simple qualitative indices that bring together key factors believed to influence the solute transport processes (Connell and Daele 2003). But there are several impediments limit the use of vulnerability-based analysis and subsequent decision making. Key limitations 
include the inability to process and manage the large volumes of data required for carrying out such analysis and the difficulty in accounting for the spatial heterogeneities associated with the systems of natural resources (Tim et al. 1996). Geographic information system (GIS) offers the tools to manage, process, analyze, map, and spatially organize the data to facilitate the vulnerability analysis. In addition to above, GIS is a sound approach to evaluate the outcomes of various management alternatives (Hall et al. 2001; Almasri 2008; Thapinta and Hudak 2003; Lake et al. 2003; Al-Adamat et al. 2003; Jordan and Smith 2005; Shirazi et al. 2013). The other key limitation is that most of the overlay and index method including the DRASTIC method does not address the uncertainties involved in groundwater vulnerability assessment. On the other hand, fuzzy techniques have the capability to address the uncertainties involved in groundwater vulnerability assessment which are ambiguous uncertainties that may be considered as a fuzzy problem. Furthermore, in standard DRASTIC method, the space between input variables is divided into explicit and fixed sets, and therefore, the DRASTIC vulnerability indices of the input variables are not continuous. Hence, any variation of input parameters in these spaces and their effect will not appear in the final output DRASTIC index. That is, the standard DRASTIC model is unable to describe a continuous transition from the easiest to be polluted to the most difficult to be polluted that is fuzziness of the groundwater vulnerability to pollution. To overcome these problems, a GIS-based fuzzy pattern recognition approach is presented to improve the DRASTIC model. The model was applied for vulnerability assessment of Ranchi district, Jharkhand, India. The research work carried out during February 2011 to January 2013 in Birla Institute of Technology, Mesra, Ranchi, India. The model outputs have continuous transition and also sensitive to the parameter variations in the discretized schemes. The process involves transformation of the different ranges or ratings of the factor images into membership function values and aggregation of the individual factor scores in GIS to create the final groundwater vulnerability to pollution map. Sensitivity analysis of the model is also demonstrated for understanding the influence of individual input variables in vulnerability index.

\section{Materials and methods}

The first step involves identification of input variables. The input variables (hydrogeological settings) considered in the model is same as that of the standard DRASTIC model. The second step is generation of thematic layers for each input parameters in GIS environment (ArcGIS 9.3). The raw data required for thematic layer generation were collected from various sources (explained in section Generation of Thematic Layers). Each of the thematic layers was fuzzified using Eq. (4). The ranges of the fuzzified layers lie between 0 and 1 . The fuzzy pattern recognition optimization model was developed for groundwater vulnerability to pollution. All the thematic layers were overlaid in GIS using the developed model to obtain the final fuzzy pattern vulnerability to pollution map. The thematic layers prepared for the existing system should also be assigned the ranges and ratings as per the standards DRASTIC model for obtaining the DRASTIC vulnerability map. The weights assigned to each hydrogeological factor are same as the normalized standard DRASTIC weights. Both the model prediction value was compared to the observed nitrate concentration in groundwater for assessing the prediction capability and validation of the model.

\section{DRASTIC model}

The DRASTIC model considers seven hydrogeological parameters: depth to water table $(D)$, net recharge $(R)$, aquifer media $(A)$, Soil media $(S)$, topography or slope $(T)$, impact of the vadose zone $(I)$, and hydraulic conductivity $(C)$ of the aquifer. DRASTIC elected to use weight for each parameter based on its relative significance contributing to the pollution potential and rating value between 1 and 10 to each parameter, except $\mathrm{R}$ which ranges between 1 and 9 is given depending on local hydrogeological settings. DRASTIC index can be determined using the Eq. (1) given below:

DRASTIC index $=\sum_{j=1}^{m}\left(w_{j} R_{j}\right)$

where $W_{j}$ and $R_{j}$ are the weights and ratings of the $j$ th hydrogeological factors (Refer Aller et al. 1987 for ratings and weights of the seven hydrogeological parameters).

The scale of DRASTIC vulnerability index can be determined from the sum of the maximum and minimum values of the sub-indices represented in Aller et al. 1987. The minimum and maximum values of the vulnerability index were computed using Eq. (1) and found to be 23 and 226, respectively. The normalized DRASTIC vulnerability index (NDVI) can be computed using Eq. (2). NDVI ranges from 0 to 1 .

$$
\begin{aligned}
& \text { Normalized DRASTIC vulnerability index (NDVI) } \\
& =(\text { Calculated index-Minimum index }) /(\text { Maximum index } \\
& - \text { Minimum index })
\end{aligned}
$$

Development of fuzzy pattern recognition optimization model

Pattern recognition can be viewed as a 2-fold task, consisting of learning the invariant and common properties of a set of samples characterizing a class, and of deciding that if a 
new sample is a possible member of the class by noting that it has properties common to those of the sample. Therefore, the task of pattern recognition can be described as a transformation from the measurement space to the feature space and finally to the decision space (Pal and Pal 2001). Fuzzy logic and fuzzy set theory introduced by Zadeh (1965) have been extensively used in ambiguity and uncertainty modeling in decision making. The basic concept in fuzzy logic is quite simple and has the capability to accommodate the uncertainty. Any statement in fuzzy logic is not only "true" or "false" but also represents the degree of truth or degree of falseness for each input. Several approaches have been used to apply fuzzy set theory to water resources problems, including fuzzy pattern recognition and optimization technique (Chen 1994; Zhou et al. 1999; Shouyu and Guangtao 2003; Mao et al. 2006), fuzzy rule-based systems (Shouyu and Guangtao 2003; Uricchio et al. 2004; Mao et al. 2006; Gemitzi et al. 2006; Afshar et al. 2007; Nobre et al. 2007; Pathak et al. 2008, Pathak and Hiratsuka 2011). Zhou et al. (1999) used a fuzzy pattern recognition model formulated by Chen (1994), which is two-level optimization model, and further, Shouyu and Guangtao (2003) developed the generalized form of above optimization model to evaluate groundwater vulnerability. Evaluation of groundwater vulnerability to pollution can be regarded as identification of the level to which a monitoring location or hydrogeological settings. If the number of samples for groundwater vulnerability to pollution assessment are $n$ and the number of influence factors leads to groundwater pollution are $\mathrm{m}$ (seven in this case), the factors matrix (X) for the samples can be written as:

$X=\left(x_{i, j}\right)_{n \times m}=\left[\begin{array}{cccc}x_{11} & x_{12} & \cdots & x_{1 m} \\ x_{21} & x_{22} & \cdots & x_{2 m} \\ \vdots & \vdots & \vdots & \vdots \\ x_{n 1} & x_{n 2} & \cdots & x_{n m}\end{array}\right]$

In the above matrix, $x_{i, j}$ is values of $j$ th factor at $i$ th location (sample).

The relative membership degree $\left(r_{i, j}\right)$ of $j$ th factor of $i$ th sample can be determined by Eq. (4) as given below:

$r_{i j}=\left\{\begin{array}{cc}\frac{x_{i j}-x_{\operatorname{minj}}}{x_{\max }-x_{\operatorname{minj}}}, & x_{i j} \in \operatorname{group} \mathrm{A} \\ 1-\frac{x_{i j}-x_{\operatorname{minj}}}{x_{\operatorname{maxj}}-x_{\operatorname{minj}}}, & x_{i j} \in \operatorname{group} \mathrm{B}\end{array}\right.$

where group A contains positively correlated hydrogeological factors $(R, A, S, I, C)$ with vulnerability, that is the higher the value of factors, the higher the vulnerability and vice versa and group B contains negatively correlated hydrogeological factors $(D, T)$ with vulnerability, that is the higher the value of factors, the lower the value of vulnerability index and vice versa.

$X_{\max j}$ and $X_{\min j}$ equal the maximum and minimum values (numeric variables) or ratings (subjective variables), respectively of $j$ th hydrogeological factors. The maximum and minimum ratings of aquifer type, soil type, and impact of vadose zone considered as 10 and 1 , respectively in the model. The minimum values $\left(X_{\min }\right)$ for all the numerical factors $(D, R, T$, and $C$ ) were considered as 0 . The maximum values $\left(X_{\max }\right)$ for $D, T$, and $C$ were considered as 30.48, $93 \mathrm{~cm}, 18 \%$, and $81.49 \mathrm{~m} /$ year, respectively. The maximum values were decided on the basis of maximum range mentioned in standard DRASTIC model.

The membership degree $\left(r_{i, j}\right)$ for a sample having value $\left(x_{i, j}\right)$ less than that of the minimum value (i.e., $\left.x_{i, j}<x_{\min }\right)$ is zero.

Similarly, the membership degree $\left(r_{i, j}\right)$ for a sample having value $\left(x_{i, j}\right)$ higher than that of the maximum value (i.e., $x_{i, j}>x_{\text {max }}$ ) is one.

Using above Eq. (4), the relative membership degree matrix $\mathrm{R}$ can be derived as:

$R=\left(r_{i, j}\right)_{n \times m}=\left[\begin{array}{cccc}r_{11} & r_{12} & \cdots & r_{1 m} \\ r_{21} & r_{22} & \cdots & r_{2 m} \\ \vdots & \vdots & \vdots & \vdots \\ r_{n 1} & r_{n 2} & \cdots & r_{n m}\end{array}\right]$

where $r_{i, j}$ is the relative membership degree of $j$ th factor $(j=1,2, \ldots, \mathrm{m})$ of $i$ th sample $(i=1,2, \ldots, \mathrm{n})$. Here, $\mathrm{m}$ is equal to seven as the model considered only seven factors which influences the groundwater pollution. In matrix $R$, if $r_{i, j}=1$, the alternative $j$ is the worst and if $r_{i, j}=0$, the alternative $j$ is the best according to the objective $i$ only. In matrix $R$, the best alternative in which all the $\mathrm{m}$ factor's membership degrees are equal to 0 , denoted by $G=\left(g_{1}\right.$, $\left.g_{2}, \ldots, g_{\mathrm{m}}\right)=(0,0, \ldots, 0)$ defined as difficult to be polluted, the worst alternative is expressed as $B=\left(b_{1}, b_{2}, \ldots\right.$, $\left.b_{\mathrm{m}}\right)=(1,1, \ldots, 1)$, called as easiest to be polluted. In this case, the decision-making problem becomes a fuzzy pattern recognition problem and the weighted distance of each alternative for which the $i$ th sample in matrix $\mathrm{R}$ belongs to ideal optimum represent the vulnerability index.

In matrix $R$, alternative $i$ can be expressed as

$r_{i}=\left(r_{i, 1}, r_{i, 2}, \ldots, r_{i, m}\right)$

The distance of sample $i$ to the "easiest to be polluted" can be described as:

$d_{i e}=\sqrt[p]{\sum_{j=1}^{7}\left[w_{j}\left(r_{i j}-1\right)\right]^{p}}$

The distance of sample $i$ to the "difficult to be polluted" can be described as:

$d_{i d}=\sqrt[p]{\sum_{j=1}^{7}\left(w_{j} r_{i j}\right)^{p}}$

In Eqs. (5) and (6), $\mathrm{p}$ is a distance parameter. For $p=1$, the distance is called Hamming distance and $p=2$, the 
Table 1 Weights of hydrogeological factors in DRASTIC and fuzzy conditions

\begin{tabular}{llllllll}
\hline Parameter & $T$ & $S$ & $A$ & $C$ & $R$ & $D$ & $I$ \\
\hline $\begin{array}{l}\text { DRASTIC weights } \\
\quad \text { Aller et al. 1987) }\end{array}$ & 1 & 2 & 3 & 3 & 4 & 5 & 5 \\
$\begin{array}{l}\text { Normalized } \\
\quad \begin{array}{l}\text { DRASTIC weights } \\
\text { for fuzzy pattern } \\
\text { recognition model }\end{array}\end{array}$ & 0.04 & 0.09 & 0.13 & 0.13 & 0.17 & 0.22 & 0.22 \\
\hline
\end{tabular}

distance is called Euclidean distance, which are commonly used for degree of differences in impact.

$W_{j}$ is the relative weight of $j$ th factor. Since the influences of various hydrogeological factors are different in the process of groundwater contamination, the weights assigned to each factor also different. The weighting vector assigned to $\mathrm{m}$ factors is denoted by $w=\left[w_{1}, w_{2}, \ldots, \mathrm{w}_{\mathrm{m}}\right]$, subject to a constraint $\sum_{j=1}^{m} w_{j}=1$. The weights of each parameter assumed to be same as that of the standard DRASTIC model. The model uses the normalized weight of the same as shown in Table 1.

If the cumulative membership degree to the best is denoted by $u_{i}$ for $i$ th alternative or hydrogeological condition, $\left(1-u_{i}\right)$ is its membership degree to the worst. In the view of fuzzy sets, the cumulative membership degree may be regarded as weight. Thus, the Eqs. (7) and (8) will better describe the differences between $i$ th alternative from the best and the worst condition, respectively. The weighted distance of the $i$ th alternative to the best can be described as

$D_{i d}=u_{i} d_{i d}=u_{i} \sqrt[p]{\sum_{j=1}^{7}\left(w_{j} r_{i j}\right)^{p}}$

Similarly, the weighted distance of the $i$ th alternative to the worst can be described as

$D_{i e}=\left(1-u_{i}\right) d_{i e}=\left(1-u_{i}\right) \sqrt[p]{\sum_{j=1}^{7}\left[w_{j}\left(r_{i j}-1\right)\right]^{p}}$

In the view of fuzzy sets, the membership degree $u_{i}$ may be regarded as weight for distance $d_{i e}$ or $d_{i d}$. The synthetic weight distance will better describe the differences in vulnerability to pollution level of $i$ th alternative (existing condition) to maximum degree of vulnerability to pollution (1) or minimum degree of vulnerability to pollution (0).

In order to acquire the optimized solution of $u_{i}$, the following objective function was used (Chen 1994):

$\min \left\{F\left(u_{i}\right)=D_{i d}^{2}+D_{i e}^{2}=u_{i}^{2} \sum_{j=1}^{7}\left[w_{j}\left(r_{i j}-1\right)\right]^{2}+\left(1-u_{i}\right)^{2} \sum_{j=1}^{7}\left(w_{j} \times r_{i j}\right)^{2}\right\}$
To solve, $\partial F\left(u_{i}\right) / \partial u_{i}=0$, then

$$
u_{i}=\frac{1}{1+\sum_{j=1}^{m}\left[w_{j}\left(r_{i j}-1\right)\right]^{2} / \sum_{j=1}^{m}\left(w_{j} r_{i j}\right)^{2}}
$$

Thus, for each hydrogeological setting, $u_{i}$ can be calculated using Eq. (10). According to this model, the lower the value of $u_{i}$, the better the alternative $i$ and vice versa.

Application to the Ranchi district, Jharkhand, India

Ranchi district lies in the southern part of Jharkhand state in India. The district has total area of $4,991 \mathrm{~km}^{2}$. The latitude and longitude of the district are $23^{\circ} 15^{\prime}-23^{\circ} 25^{\prime} \mathrm{N}$ and $85^{\circ} 15^{\prime}-85^{\circ} 25^{\prime} \mathrm{E}$, respectively and falls in Survey of India toposheet 73E/7. The district comprises of 14 blocks namely Ormanjhi, Kanke, Ratu, Bero, Burmu, Lapung, Chanho, Mandar, Bundu, Tamar, Angara, Sonahatu, Silli, and Namkum as shown in Fig. 1.

As per 2011 population census, the total population of Ranchi was 2,912,022 (Census of India 2011). The population growth rate in Ranchi was high $(23.9 \%)$ as compared to national growth rate $(21.15 \%)$ in the last decade (2001-2011). Due to the rising population and growing economy in agriculture, industry, and other sectors, the demand for freshwater is increasing rapidly in Ranchi, and the domestic water demand was estimated to be 58.81 million cubic meter $(\mathrm{mcm})$ at the rate of 135 liter per capita per day (lpcd) in 2011 [Central Ground Water Board (CGWB 2011)]. It has also been worked out that about $30 \%$ of the total water demand was met from ground water (CGWB 2011). Altitude of the area varies from 500 to $700 \mathrm{~m}$ above mean sea level with regional slope of the area toward east. But there are many hillocks through the district having altitude above $700 \mathrm{~m}$ from mean sea level. Average regional slope is $1-3$ which is indicative of flat or low slope profile (CGWB 2011). The humid tropical climate has led to the formation of red soil in areas of higher elevation. This is overlain by lateritic soil. The area underlain by schistose rocks is having more deep red soil than those of granitic rocks due to the dominance of mafic minerals, particularly garnet. Soils of granitic rocks are lighter in color due to the leaching of felsic components present in the rocks (CGWB 2011). Ranchi district experiences subtropical climate, which is characterized by hot summer season from March to May and well-distributed rainfall during monsoon season from June to October. Winter season in the area is marked by dry and cold weather during the month of November to February. The district is having varied hydrogeological characteristics due to which groundwater potential differs from one region to 

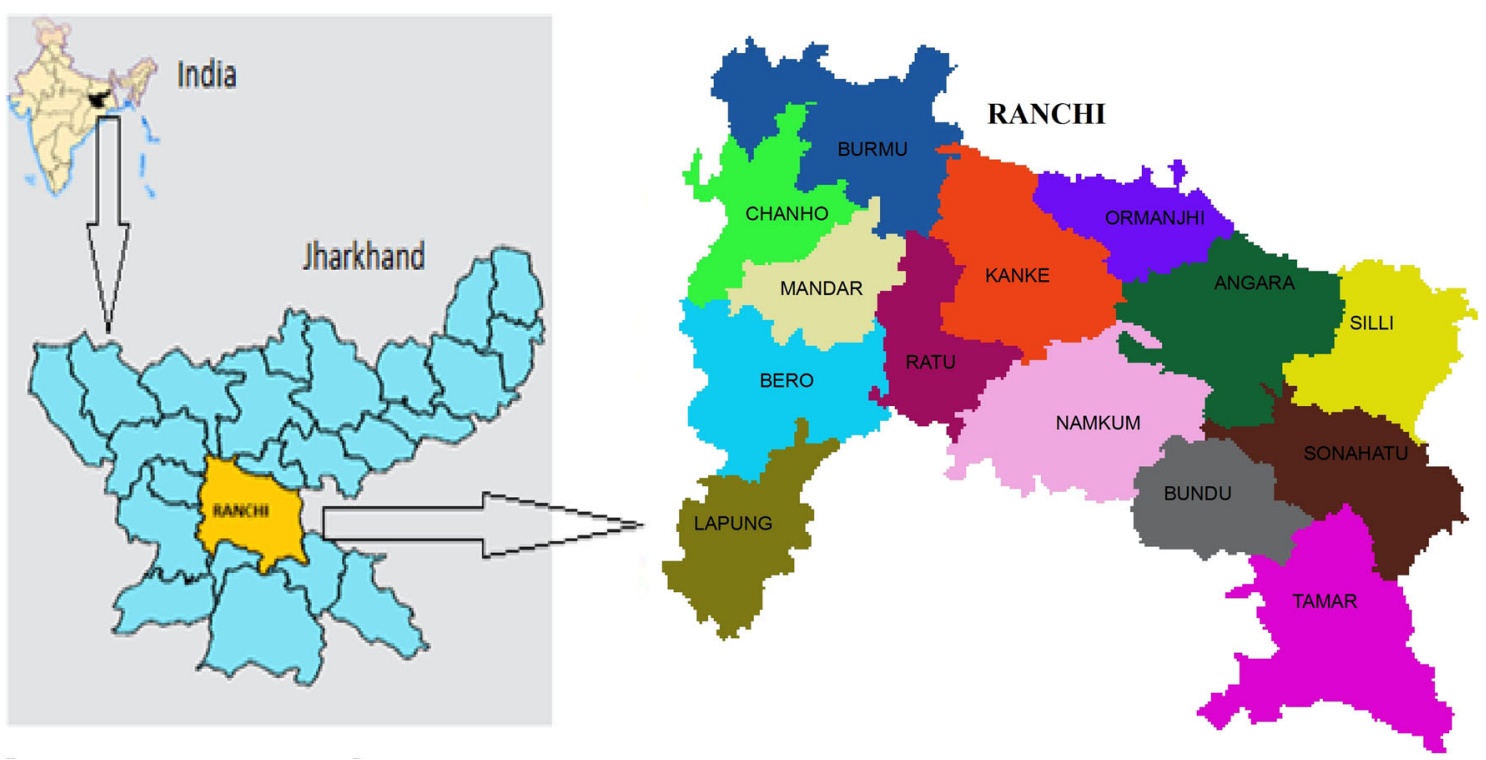

Fig. 1 Study area map

another. It is underlain by Chotanagpur granite gneiss of pre-Cambrian age in three-fourth of the district (CGWB 2011). In Ratu and Bero blocks thick lateritic capping is placed above granite gneiss. A big patch of older alluvium is found in Mandar block extending in Brombay, Murma areas. Khelari (northernmost portion) area consists of limestone rocks. Two types of aquifers (weathered aquifer and fractured aquifers) are observed in Ranchi district (CGWB 2011).

\section{Generation of thematic layers}

Thematic layers of each of the seven hydrogeological parameters were generated using ArcGIS software. Raw data collected from various sources like water depth in well (real time observation using tape and GPS meter), geologic map (collected from CGWB, Patna), rain fall data (collected from Indian Meteorological Department (IMD), Pune), soil map (collected from Birsa Agricultural University (BAU), Ranchi), and SRTM data [United States Geological Survey (USGS) web site] were processed in GIS for the generation of individual thematic layer. The procedure for the generation of individual thematic layer generation is explained below.

Depth to water table $(D)$ The thematic map of depth to water table obtained from measured data of depth to water level in 29 wells using a tape from different locations in the study area. The depth to water table at 29 monitoring locations along with the value of other hydrological factors and their corresponding ratings in the same locations are reported in Table 2. The latitude and longitude of the well locations were measured using a handheld GPS (GARMIN make) meter. These point data were added into the base map and interpolated using Inverse Distance Weighted method (IDW) method to obtain the thematic map. The depth to water table ranges from 2 to $15 \mathrm{ft}$. in the study area.

Net recharge $(R)$ Net recharge value can be estimated using field experiments, hydrological precipitation-runoff models, or simply by multiplying the difference of the spatial distribution of evapotranspiration and the spatial distribution for mean annual rainfall by an infiltration coefficient (Elçi 2010). According to Pathak et al. (2009), the shallow aquifer recharged mainly by direct infiltration from precipitation; therefore, net recharge was estimated by using formula of net recharge equals to the summation of evaporation and runoff are subtracted from rainfall. The average blockwise precipitation data were collected from IMD, India and added into base map to generate precipitation or rainfall map. Since the actual evaporation data for the study area is not available, it was estimated roughly on the basis of past studies (Singh and Pawar 2012; Pathak et al. 2009). The evapotranspiration rate considered for the analysis is $5 \%$ of the precipitation. The value reflects the daily evapotranspiration rate in the rainy season rather than the annual evapotranspiration rate. This is because pollutant transportation to groundwater or recharge rate during non-rainy seasons is negligible. The land use map of the study area was prepared and reclassified into five categories as agricultural land, built-up area, forest area, waste land, and water body. The runoff coefficient assigned to different categories ranges from 0 to 1 depending on the land use types. The values were selected on the basis of rational formula for runoff coefficient (Source: http://water. me.vccs.edu/courses/CIV246/table2b.htm). 


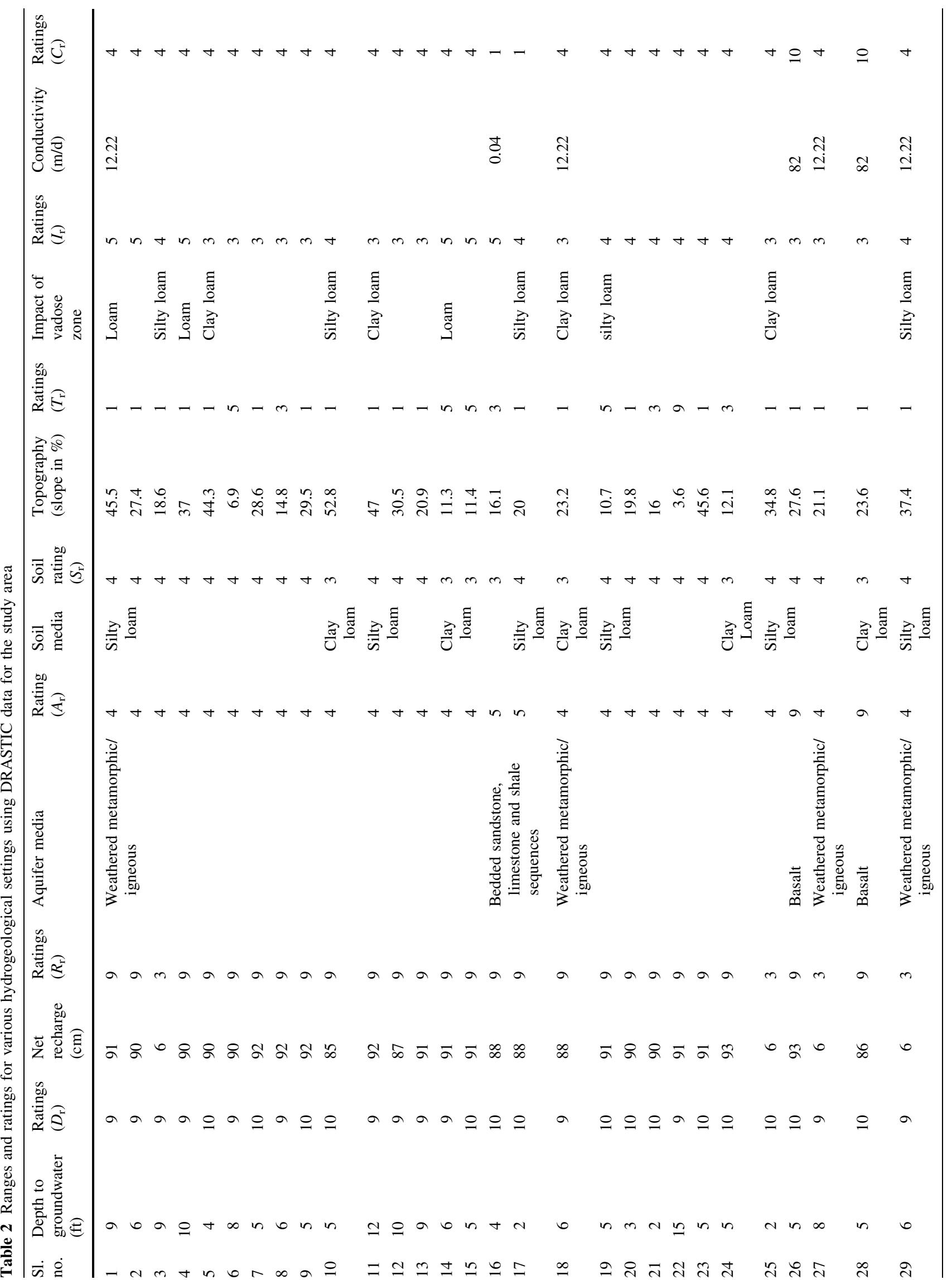


The net recharge map was derived in GIS using the formula as:

Net recharge $=$ Precipitation $-0.05 \times$ Precipitation - Precipitation $\times$ Run off coefficients

The thematic map for net recharge obtained using Eq. (11).

Aquifer media (A) The thematic map of aquifer media was prepared from the geological map (collected from Central Ground Water Board, Patna) of Ranchi district. Aquifer types in the study area were reclassified into four types (metamorphic/igneous, glacial till, sandstone/limestone, and basalt), and their corresponding numerical ratings were assigned for each aquifer media as given in Table 2.

Soil media $(S)$ Soil media map was prepared from the soil map (collected from BAU, Ranchi) of Ranchi district. The study area consists of fine to coarse loamy type soil. The soil types in the study area were classified into three types (clay loam, silty loam, and loam), and their corresponding ratings were assigned as per the Table 2.

Topography $(T)$ The topography map of the area was prepared using the Shuttle Radar Topography Mission (SRTM) data. The percentage slope raster file was created from Digital Elevation Model (DEM) using Spatial Analyst. The slope in the study area varies from 0 to 100 percent.

Impact of vadose zone (I) Due to unavailability of vadose zone data in the study area, information of the soil media was used to derive the approximate ratings for vadose zone

Hydraulic conductivity $(C)$ Due to unavailability of hydraulic conductivity data in the study area, information of the aquifer media was used to derive the hydraulic conductivity map.

Fuzzification of thematic layers

Each of the seven thematic layers $(D, R, A, S, T, I, \&$ $C)$ were fuzzified using Eq. (3). The range of the each fuzzified layer varies from 0 to 1 .

Generation of fuzzy pattern recognition groundwater vulnerability map

The final fuzzy pattern groundwater vulnerability to pollution map was obtained by overlaying the seven fuzzified thematic layers in GIS using the fuzzy pattern recognition model represented in Eq. (10). The final fuzzy pattern vulnerability to pollution map thus obtained is shown in Fig. 2.

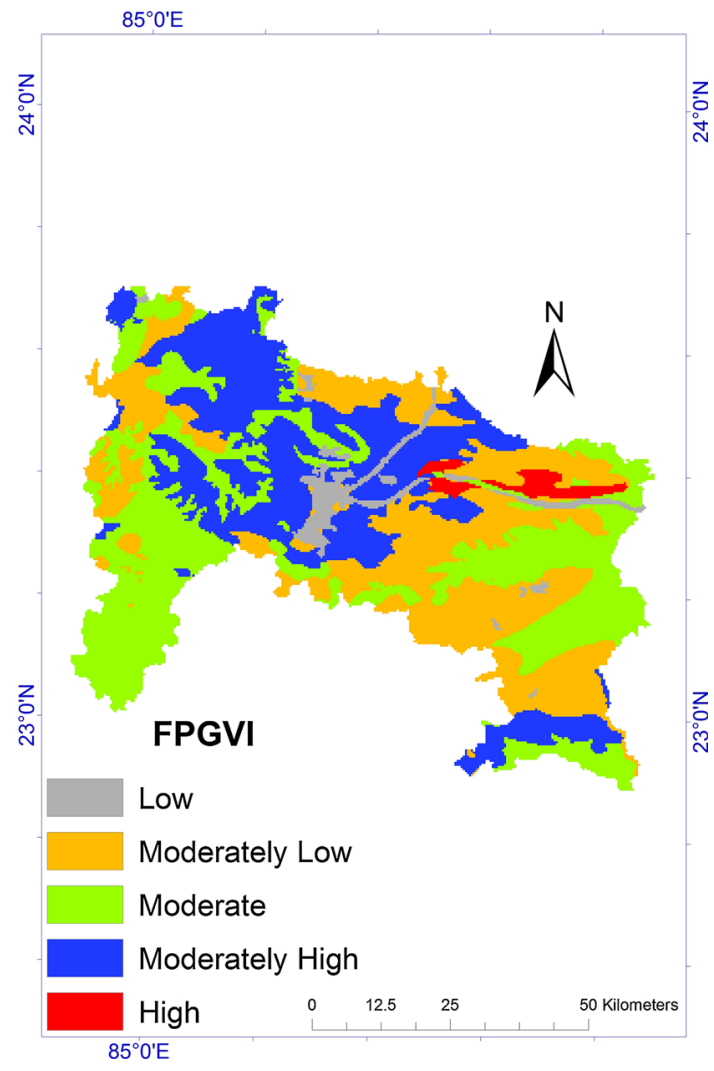

Fig. 2 Fuzzy pattern recognition groundwater vulnerability to pollution index (FPGVI) map

Generation of groundwater vulnerability to pollution map using standard DRASTIC model

The thematic maps of each of the numerical variables $(D$, $R, T$, and $C$ ) were reclassified into ranges that fit the DRASTIC model and assigned their corresponding ratings as per the Table 2. The thematic maps of each of the qualitative or subjective variables $(A, S$, and $I)$ are same as used in fuzzy pattern recognition model. The final vulnerability to pollution map was obtained by overlaying the seven thematic layers using the standard DRASTIC Eq. (1) in GIS environment is shown in Fig. 3.

\section{Results and discussion}

The groundwater vulnerability map of Ranchi district has been derived using the developed GIS-based fuzzy pattern recognition model which reflects an aquifer's inherent capacity to become contaminated. The map was derived from seven fuzzified thematic layers is shown in Fig. 2. Figure 2 clearly indicates that the fuzzy pattern groundwater vulnerability to pollution indices (FPGVI) value ranged from 0.35 to 0.83 . A high index value indicates the capacity of the hydrogeological 


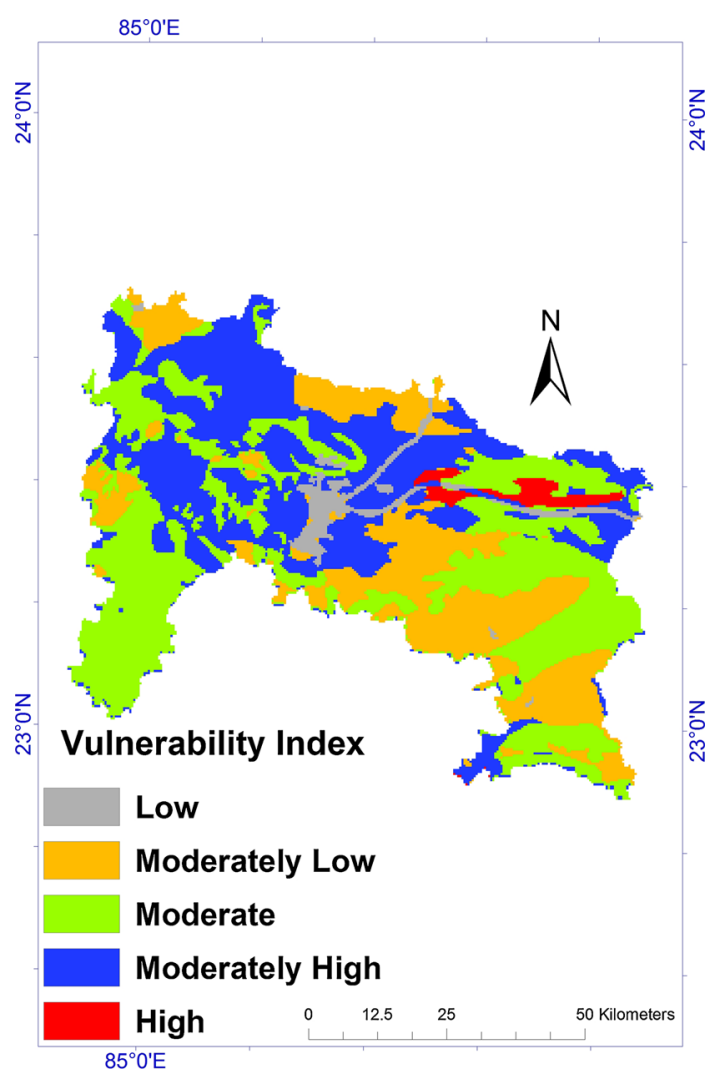

Fig. 3 DRASTIC groundwater vulnerability to pollution index (NDVI) map

environment and the landscape factors to readily move waterborne contaminants into the groundwater, whereas a low index value represents that groundwater is better protected from contaminant leaching by the natural environment. Since the membership function values ranges from 0 to 1 and the sum of the weights of the seven factors is 1 , the possible minimum and maximum value of FPGVI are $0-1$, respectively, that is the value of FPGVI ranges from 0 to 1 . This clearly indicates that when the membership function values of all the seven factors are 0 (minimum) then the value of FPGVI is 0 (minimum) and when the membership function values of all the seven factors are 1 (maximum) then the value of FPGVI is 1 (maximum). Zero indicates no threat to groundwater pollution, and one indicates maximum threat to groundwater pollution. A regional scale has been used for comparing the relative vulnerability of groundwater resources. Thus, the range of the vulnerability indices was reclassified into five classes (low, moderately low, moderate, moderately high, and high) on the basis of Jenks natural breaks that describe the relative probability of contamination of the groundwater resources. The range of the indices (FPGVI) of five vulnerability classes are: low groundwater vulnerability risk zone $(0.35-0.46)$, moderately low vulnerability risk zone $(0.46-0.54)$, moderate vulnerability zone $(0.54-0.59)$, moderately high vulnerability zone $(0.59-0.67)$, and high vulnerability zone $(0.67-0.83)$. The results reveal that the percentage of area (total area) under different vulnerability classes are $3.64 \%\left(181.39 \mathrm{~km}^{2}\right)$, $30.78 \%\left(1,535.68 \mathrm{~km}^{2}\right), 35.52 \%\left(1,772.25 \mathrm{~km}^{2}\right), 28.17 \%$ $\left(1,405.82 \mathrm{~km}^{2}\right)$, and $1.90 \%\left(94.58 \mathrm{~km}^{2}\right)$ for low, moderately low, moderate, moderately high and high, respectively. A portion of the blocks of Angara and Silli fall in the class of high vulnerable zones. On the other hand, the results of the DRASTIC model indicate that the percentage of total area under different vulnerability classes are $3.45 \%\left(168.13 \mathrm{~km}^{2}\right)$, $22.12 \%\left(1,075.45 \mathrm{~km}^{2}\right), 38.85 \%\left(1,890.99 \mathrm{~km}^{2}\right), 33.63 \%$ $\left(1,636.96 \mathrm{~km}^{2}\right)$, and $1.85 \%\left(94.97 \mathrm{~km}^{2}\right)$ for low, moderately low, moderate, moderately high and high, respectively. This clearly indicates the variations in the results of the two models.

It is very difficult to say the influences of individual parameter on the spatial changes in the vulnerability index without sensitivity analysis. This is because, variation in one individual factor has very insignificant role in the variation of vulnerability indices. To understand the influence of each parameter, sensitivity analysis was carried out. It is explained in the next section.

Validation of the model and comparison with the standard DRASTIC model

Nitrate contamination and the associated health concerns are one of the most common problems adversely affecting groundwater quality worldwide (Canter 1997). Nitrate is a highly mobile contaminant that originates from a variety of point and non-point sources (Qi and Gurdak 2006). Nitrate contamination of groundwater resources is increasing because of the increase in sources such as agricultural practices and industrial activities (Korom 1992). In the past, many scientists validated the groundwater vulnerability to pollution model with the similar range of numbers [Thirumalaivasan et al. (2003) validated the AHP-DRASTIC model by 31 samples, and Shahid and Hazarika (2007) validated the DRASTIC model by 29 samples]. The model was validated by comparing the model output with the measured nitrate concentration in groundwater in the study area. The hydrogeological data at 29 points in the study area were collected and represented in Table 2. Groundwater samples were collected from 29 locations in the study area and analyzed in laboratory for nitrate concentrations. The spatial locations of the sampling points were recorded by a hand held GPS meter. Nitrate analysis was done as per standard methods (Eaton et al. 1995). Nitrate concentrations were found to be in the range of $11.6-51.3 \mathrm{mg} / \mathrm{l}$ in the study area. The fuzzy pattern groundwater vulnerability to pollution indices (FPGVI) was calculated from the developed model for the observed hydrogeological settings at 29 locations. The comparative DRASTIC indices values for the observed hydrogeological settings also calculated using Eq. (1) and converted into normalized DRASTIC index 


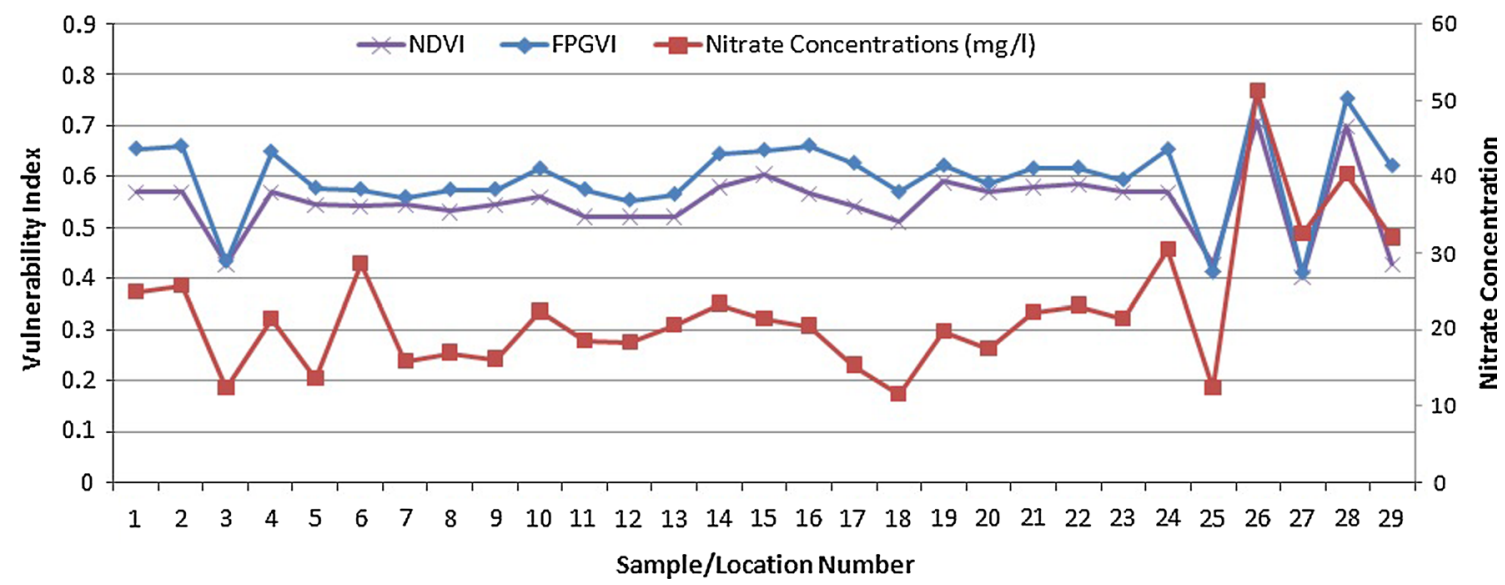

Fig. 4 Vulnerability indices versus nitrate concentration

(NDVI) using Eq. (2). The vulnerability indices obtained from the GIS-based fuzzy pattern model, and the DRASTIC model were compared to the observed nitrate concentrations for the validation of the model. The comparative values of the FPGVI, NDVI, and the nitrate concentration levels for 29 observed data sets were represented graphically in Fig. 4. The correlation analyses for three variables (NDVI, FPGVI, and nitrate concentrations) were carried out using Pearson two-tailed correlation analysis using SPSS Statistics software version 21. It was found that the correlation between the FPGVI and nitrate concentration was higher (0.566) in comparison with that of the NDVI and observed nitrate concentration (0.481). The correlation between FPGVI and nitrate concentrations is significant at $0.1 \%$ level, whereas the correlation value between NDVI and nitrate concentrations is significant at $0.8 \%$ level. The graphical representation clearly reveals that the FPGVI values shows continuous transition and closely matched with the observed nitrate concentration than that of the DRASTIC indices and observed nitrate concentration. Thus, the developed method can be used for the better prediction of groundwater vulnerability to pollution than the existing assessment method. The limitation of the developed model is that it is designed for fixed range of the hydrogeological variables. After a certain range, the model will give constant output. The other limitation is that for accommodating a new variable in the model, the weights of the variables have to be recalculated.

Sensitivity analysis of the model

The ideas or views of scientists' conflicts in regards to weights and ratings assigned to various hydrogeological factors considered for groundwater vulnerability to pollution assessment. Some scientists argue that groundwater vulnerability assessment may be worked out without using
Table 3 Statistics of single parameter removal sensitivity analysis

\begin{tabular}{lllll}
\hline Parameter & $\begin{array}{l}\text { Minimum } \\
\text { value }\end{array}$ & $\begin{array}{l}\text { Maximum } \\
\text { value }\end{array}$ & Mean & $\begin{array}{l}\text { Standard deviation } \\
\text { (SD) }\end{array}$ \\
\hline$D$ & 0.001 & 0.045 & 0.029 & 0.005 \\
$R$ & 0.000 & 0.041 & 0.005 & 0.005 \\
$A$ & 0.005 & 0.023 & 0.017 & 0.002 \\
$S$ & 0.008 & 0.025 & 0.015 & 0.002 \\
$T$ & 0.008 & 0.020 & 0.013 & 0.001 \\
$I$ & 0.010 & 0.054 & 0.030 & 0.007 \\
$C$ & 0.002 & 0.035 & 0.026 & 0.004 \\
\hline
\end{tabular}

all the parameters of the standard DRASTIC model (Barber et al. 1993; Merchant 1994), while some others not agreed with the ideas (Napolitano and Fabbri 1996). In order to make a common consensus, sensitivity analysis of the model and groundwater contamination analysis are carried out. Sensitivity analysis provides valuable information on the influence of rating values and weights assigned to each parameter (Gogu and Dassargues 2000). Lodwik et al. (1990) defined the map removal sensitivity measure that represents the sensitivity associated with removing one or more maps. The sensitivity test identifies the sensitivity of vulnerability map by removing one or more layer maps and is worked out using the following Eq. (12):

$S_{i}=\left|\frac{V_{i}}{N}-\frac{V_{x_{i}}}{n}\right|$

where $S_{i}$ is sensitivity (for $i$ th unique condition subarea) associated with the removal of one map (of parameter $X$ ), $V_{i}$ is vulnerability index computed using Eq. (10) on the $i$ th sub-area, $V_{x i}$, vulnerability index of the $i$ th subarea excluding one map layer, $N$ number of map layers used to compute vulnerability index and $n$, number of map layers used for sensitivity analysis. The single parameter sensitivity test was carried out to assess the influence of each of the seven parameters of the model on the vulnerability measure. 
Table 4 Theoretical and effective weights of hydrogeological factors

\begin{tabular}{|c|c|c|c|c|c|c|c|}
\hline \multirow[t]{2}{*}{ Parameter } & \multirow[t]{2}{*}{ Theoretical weight } & \multirow[t]{2}{*}{ Theoretical weight $(\%)$} & \multirow[t]{2}{*}{ Variation index $\left(\operatorname{Var}_{\mathrm{i}}\right)$} & \multicolumn{4}{|c|}{ Effective weight (\%) } \\
\hline & & & & Min & Max & Mean & $\mathrm{SD}$ \\
\hline$D$ & 0.22 & 22.00 & 0.11 to 0.85 & 25.48 & 56.88 & 37.27 & 3.90 \\
\hline$R$ & 0.17 & 17.00 & -0.27 to 0.21 & 6.94 & 37.19 & 29.53 & 4.36 \\
\hline$A$ & 0.13 & 13.00 & -0.08 to 0.09 & 6.48 & 20.70 & 8.35 & 1.67 \\
\hline$S$ & 0.09 & 9.00 & -0.06 to 0.01 & 2.44 & 8.25 & 4.92 & 1.08 \\
\hline$T$ & 0.04 & 4.00 & -0.01 to 0.03 & 0.04 & 9.06 & 4.79 & 1.17 \\
\hline$I$ & 0.22 & 22.00 & -0.33 to 0.00 & 6.69 & 22.56 & 12.76 & 2.86 \\
\hline$C$ & 0.13 & 13.00 & -0.19 to 0.12 & 0.00 & 23.29 & 1.41 & 2.54 \\
\hline
\end{tabular}

Table 3 shows statistics of map removal sensitivity analysis that was performed by removing one or more data layer. The statistical analyses shown in Table 3 confirm the most sensitive to contamination was the parameter $I$ and $D$ followed in importance by parameters $C, A, S, T$, and $R$. The highest mean value was associated with the impact of vadose zone and depth to water table (0.030 and 0.29, respectively), and net recharge shows the lowest sensitive value $(0.005)$.

In order to assess the magnitude of the variation created by removal of one parameter, the variation index was computed using Eq. (13) as given below:

$\operatorname{Var}_{i=}\left(\frac{V_{i}-V_{x_{i}}}{V_{i}}\right) \times 100$

where $\operatorname{Var}_{i}$ is variation index of the removal parameter, and $V_{i}$ and $V_{x i}$ are vulnerability index computed using developed fuzzy pattern recognition model and vulnerability index of the study area excluding one map layer, respectively. This variation index measures the effect of the removal of each parameter. Its value can be positive or negative, depending on vulnerability index. Variation index directly depends upon the weighting system.

While the map removal sensitivity analysis presented above has confirmed the significance of the seven parameters in the assessment of the fuzzy pattern groundwater vulnerability index for the study area, the single parameter sensitivity analysis compares their "effective" weights with their "theoretical" weights (Babiker et al. 2005). The single parameter sensitivity test was carried out to assess the influence of each of the seven parameters of the model on the vulnerability measure. The effective weight of a parameter in a sub-area was calculated by using following Eq. (14):

$W_{x i=}\left(\frac{X_{r i} \times X_{w i}}{V_{i}}\right) \times 100$

where $X_{r i}$ and $X_{w i}$ are the rating values and the weights for the parameter $X$ assigned in subarea, respectively, and $V_{i}$ is the vulnerability index calculated using Eq. (12) in the subarea.
The "effective" weight is a function of the other six parameters as well as the weight assigned to it in the fuzzy pattern recognition model for vulnerability assessment. The "effective" weights of the seven hydrogeological parameters exhibited some deviation from the "theoretical" weight (Table 4). The depth to water $(D)$ tends to be the effective parameter in the vulnerability assessment with an average weight of $37.27 \%$ against the "theoretical" weight $(22 \%)$. The "effective" weight of the net recharge parameter, $R(29.53 \%)$ exceeds the "theoretical" weight assigned in the original model (17\%). These two parameters have major role on vulnerability, whereas the effective weight of topography is $4.79 \%$ against the $4 \%$ of theoretical value. Comparing with the "theoretical" weights, the "effective" ones show huge differences in the case of depth to water and the net recharge parameters. This pattern was may be due to the availability of groundwater at shallow depth and the high recharge. On the other hand, the effective weights of the aquifer media $(8.35 \%)$, soil media (4.92\%), impact of vadose zone $(12.76 \%)$, and hydraulic conductivity $(1.41 \%)$ were less than the corresponding "theoretical" weights $(D$ : $13 \%, A: 9 \%, I: 22 \%$, and $C: 13 \%$ ).

Application of fuzzy-AHP for understanding the decision-making attitude for groundwater protection

The weight determination of various hydrogeological factors primarily depends on subjective judgment (or preference) of the design team. In such a situation, it is difficult to incorporate preference scales (such as "less likely", "more likely") in the analytical models. In fact, the meaning of "preference" is already embedded in fuzziness and human semantics. Therefore, using a crisp value for pairwise comparison is not suitable because it does not accurately represent the individual semantic cognition state of the decision makers. Thus, a fuzzy-AHP approach was used for determining the weights of various hydrogeological factors for understanding the decision-maker's attitude. In the fuzzy-AHP model, instead of being discrete, the numbers 1-9 represent triangular fuzzy numbers, which 
were used to capture the subjectivity or vagueness of the pairwise preferences of attributes considered for groundwater vulnerability to pollution. The intensity of importance definition is in accordance with the description proposed by Saaty $(1977,1980)$. Satty's scale was used for representation of qualitative comparison into numerical terms and fuzzy values of relative importance to cover uncertainty. Introduction of $\alpha$ was done for construction of fuzzy comparison matrix that improves the scaling scheme of Satty method. For this example, the value of fuzzification factor $\alpha$ is assumed " 1 ", i.e., 3 meaning a $\operatorname{TFN}(2,3$, 4). This will give lower and upper comparison element for comparison matrix. Value of $\alpha$ can be assumed, on the basis of certainty of situation. The steps of fuzzy-AHP method are explained below:

Step 1: Develop fuzzy judgment matrix using pairwise comparisons Having defined the membership functions for the fuzzy set, the fuzzy judgment matrix is constructed to represent the pairwise preference of parameters (considered for groundwater to vulnerability to pollution). In its general form, the fuzzy judgment matrix takes the following form.

$$
A=\left(\begin{array}{ccccc}
1 & \tilde{a}_{12} & \tilde{a}_{13} & \cdots & \tilde{a}_{1 n} \\
1 / \tilde{a}_{12} & 1 & \tilde{a}_{23} & \cdots & \tilde{a}_{2 n} \\
\cdots & \cdots & 1 & \cdots & \cdots \\
\cdots & \cdots & \cdots & \cdots & \cdots \\
1 / \tilde{a}_{1 n} & \cdots & \cdots & \cdots & 1
\end{array}\right)
$$

where $\tilde{a}_{i j}=\tilde{1}, \tilde{3}, \tilde{5}, \tilde{7}, \tilde{9}$, these number are similar to the pairwise comparison scales as defined by Saaty (1977) but are fuzzy in nature. Where $\tilde{a}_{i j}>0 ; \quad \tilde{a}_{i j}=1 / \tilde{a}_{j i} ; \quad \tilde{a}_{i i}=1$. The fuzzy pairwise comparison matrix developed for groundwater vulnerability assessment variables is represented below in matrix $\tilde{A}$

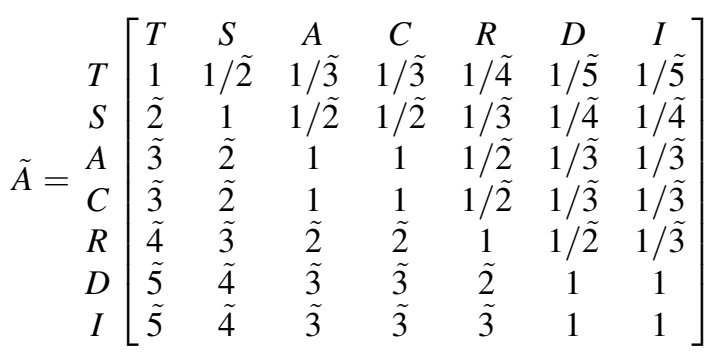

Step 2: Generation of crisp comparison matrix The fuzzy comparison matrix can be converted to a crisp matrix using following Eq. (15) (Lee 1999).

$\tilde{a}_{i j}^{\alpha}=\lambda a_{i j u}^{\alpha}+(1-\lambda) a_{i j l}^{\alpha}$

where $a_{i j u}^{\alpha}$ and $a_{i j l}^{\alpha}$ are upper and lower fuzzy value of comparison element $\tilde{a}_{i j}^{\alpha}$. These are giving a defuzzified value $\tilde{a}_{i j}^{\alpha}$ and will form crisp comparison matrix. The value of $\lambda$ reflects the attitude of decision maker toward the fuzziness in the judgment. Accordingly, when $\lambda$ approaches to 0 , it reflects groundwater resources manager's attitude inclined toward more moderate values or underestimation of the crisp value. Alternatively, $\lambda$ approaching to 1 reflects that the manager's attitude is inclined toward more extreme values or an overestimation of the crisp value. In this work, three cases were analyzed to understand the decision-making attitude of groundwater resources manager $(\lambda=0.95$ considered for pessimistic decision-making attitude; $\lambda=0.5$ considered for compromising decision-making attitude; and $\lambda=0.05$ considered for optimistic decision-making attitude).

Therefore, using Eq. (15), we can convert the fuzzy judgment matrix into its crisp form by substituting the values for $\alpha$ and $\lambda$. The value of fuzzification factor $(\alpha)$ considered for the analysis was 0.5 . Matrices $A_{m}, A_{o}$, and $A_{p}$ represents crisp matrices for most likely, optimistic, and pessimistic conditions, respectively.

$A_{m}=\begin{gathered}S \\ T \\ S \\ C \\ C \\ R \\ D \\ I \\ I\end{gathered}\left[\begin{array}{ccccccc}T & S & A & C & R & D & I \\ 1 & 0.66 & 0.37 & 0.26 & 0.25 & 0.2 & 0.2 \\ 3 & 2 & 0.66 & 0.29 & 0.33 & 0.22 & 0.22 \\ 3 & 2 & 1 & 0.66 & 0.5 & 0.37 & 0.37 \\ 5 & 4 & 2 & 1 & 0.5 & 0.37 & 0.37 \\ 5 & 4 & 3 & 2 & 2 & 1 & 1 \\ & & & 3 & 3 & 1 & 1\end{array}\right]$

$A_{o}=\begin{gathered}S \\ T \\ S \\ C \\ R \\ R \\ D \\ I\end{gathered}\left[\begin{array}{ccccccc}T & S & A & C & R & D & I \\ 1 & 0.96 & 0.48 & 0.48 & 0.32 & 0.24 & 0.24 \\ 2.9 & 1 & 0.96 & 0.96 & 0.32 & 0.24 & 0.24 \\ 3.9 & 2.9 & 1 & 0.97 & 0.96 & 0.48 & 0.48 \\ 4.9 & 3.9 & 1.9 & 1 & 0.96 & 0.48 & 0.48 \\ 5.9 & 4.9 & 2.9 & 2.9 & 1 & 0.96 & 0.48 \\ 5.9 & 4.9 & 3.9 & 3.9 & 2.9 & 1 & 0.97 \\ \end{array}\right.$

$$
A_{p}=\begin{gathered}
T \\
S \\
C \\
C \\
R \\
D \\
I \\
I
\end{gathered}\left[\begin{array}{ccccccc}
T & S & A & C & R & D & I \\
1 & 0.36 & 0.26 & 0.26 & 0.2 & 0.17 & 0.17 \\
1.1 & 1 & 0.36 & 0.36 & 0.25 & 0.2 & 0.2 \\
2.1 & 1.1 & 1 & 0.52 & 0.36 & 0.26 & 0.26 \\
3.1 & 2.1 & 0.1 & 1 & 0.36 & 0.26 & 0.26 \\
4.1 & 3.1 & 2.1 & 1.1 & 1 & 0.36 & 0.26 \\
4.1 & 3.1 & 2.1 & 2.1 & 1.1 & 1 & 0.52 \\
& & & & & & 1
\end{array}\right]
$$

Step 3: Check for consistency The pairwise comparisons of the fuzzy judgment matrix are prone to inconsistency and error in the preference responses of people (Zahedi 1986), and as a result often become inconsistent. The AHP introduces a consistency measure to avoid this problem and estimate the relative weight in the presence of inconsistency in responses. Saaty $(1977,1980)$ has shown that in a consistent judgment matrix, $\lambda_{\max }=n$, where $\mathrm{n}$ is the dimension of the judgment 
matrix, and $\lambda_{\max }$ is maximum Eigen value of matrix. Consistency index $(\mathrm{CI})$ indicates whether a decision maker provides consistent values (comparisons) in a set of evaluation. The CI is determined using Eq. (16) as given below:

$\mathrm{CI}=\frac{\lambda_{\max }-n}{n-1}$

The final inconsistency in the pairwise comparisons is solved using consistency ratio $\mathrm{CR}=\mathrm{CI} / \mathrm{RI}$, where $\mathrm{RI}$ is the random index, which is obtained by averaging the CI of a randomly generated reciprocal matrix (Saaty 1980). The value of RI is 1.32. The threshold of the CR is $10 \%$, and in case of exceedance a three-step procedure is followed (Saaty 2005): (1) identify the most inconsistent judgment in the decision matrix, (2) determine a range of values the inconsistent judgment can be changed to so that would reduce the associated inconsistency, and (3) ask the decision maker to reconsider the judgment to a 'reasonable value'. In this paper, though the pairwise comparison indices (relative importance) of the judgment matrix are TFNs; however, the CI is evaluated for the most likely conditions. Consistency ratio for the most likely conditions was found to be 0.05 , which is less than 0.1 (recommended by Satty for accepting the pair-wise comparison matrix). Eigen value and vector of crisp matrix was calculated using MATLAB software.

Step 4: Calculate the fuzzy weights Weights of input parameters can be obtained through determination Eigen values of comparison matrix (Saaty 2000). Maximum Eigen value $\left(\lambda_{\max }\right)$ of crisp matrix $A$ can be calculated using characteristic equation $|A-\lambda I|=0$. Now, substitution of $\lambda_{\max }$ in equation, $\mathrm{AX}=\lambda_{\max } X$, this will give corresponding Eigen value of $A$. Here, $A$ is $n \times n$ matrix, and $X$ is $n \times 1$ matrix.

$$
\begin{aligned}
X_{m} & =\left[\begin{array}{ccccccc}
T & S & A & C & R & D & I \\
-0.09 & -0.13 & -0.22 & -0.22 & -0.36 & -0.58 & -0.63
\end{array}\right] \\
X_{o} & =\left[\begin{array}{ccccccc}
T & S & A & C & R & D & I \\
-0.09 & -0.13 & -0.22 & -0.24 & -0.37 & -0.55 & -0.64
\end{array}\right] \\
X_{p} & =\left[\begin{array}{ccccccc}
T & S & A & C & R & D & I \\
0.1 & 0.14 & 0.22 & 0.2 & 0.35 & 0.6 & 0.62
\end{array}\right]
\end{aligned}
$$

Matrices $X_{\mathrm{m}}, X_{o}$, and $X_{p}$ represent Eigen vectors for crisp matrices $A_{m}, A_{o}$, and $A_{p}$, respectively. Normalization of Eigen vector will represent relative importance of individual parameters, which are represented by matrices $A_{w m}, A_{w o}$ and $A_{w p}$, respectively.

$$
\begin{aligned}
A_{w m} & =\left[\begin{array}{ccccccc}
T & S & A & C & R & D & I \\
0.041 & 0.059 & 0.101 & 0.101 & 0.159 & 0.256 & 0.278
\end{array}\right] \\
A_{w o} & =\left[\begin{array}{ccccccc}
T & S & A & C & R & D & I \\
0.039 & 0.058 & 0.099 & 0.108 & 0.164 & 0.244 & 0.285
\end{array}\right] \\
A_{w p} & =\left[\begin{array}{ccccccc}
T & S & A & C & R & D & I \\
0.047 & 0.064 & 0.099 & 0.09 & 0.157 & 0.265 & 0.274
\end{array}\right]
\end{aligned}
$$

Each of the parameters considered in the model has different influence on groundwater vulnerability to pollution and hence their relative weights are also different. The weights of the parameters were determined

\begin{tabular}{|c|c|c|c|c|c|c|c|}
\hline Parameter & $T$ & $S$ & $A$ & $C$ & $R$ & $D$ & $I$ \\
\hline Fuzzy weights (optimistic decision-making attitude) & 0.039 & 0.058 & 0.099 & 0.108 & 0.164 & 0.244 & 0.285 \\
\hline Fuzzy weights (compromising decision-making attitude) & 0.041 & 0.059 & 0.101 & 0.101 & 0.159 & 0.256 & 0.278 \\
\hline Fuzzy weights (pessimistic decision-making attitude) & 0.047 & 0.065 & 0.100 & 0.091 & 0.158 & 0.265 & 0.275 \\
\hline
\end{tabular}
in three conditions are listed in Table 5.

The vulnerability index maps were derived under three conditions (compromising attitude, optimistic attitude, and pessimistic attitude). In three different conditions, different sets

Table 5 Weights of hydrogeological factors under different decision-making attitude

Table 6 Characteristics of groundwater vulnerability maps in three conditions

\begin{tabular}{lccccccc}
\hline $\begin{array}{l}\text { Vulnerability } \\
\text { index }\end{array}$ & FPGVI & $\begin{array}{l}\text { Area }\left(\mathrm{km}^{2}\right) \text { in } \\
\text { most likely } \\
\text { condition }\end{array}$ & $\begin{array}{l}\text { Area }(\%) \text { in } \\
\text { most likely } \\
\text { condition }\end{array}$ & $\begin{array}{l}\text { Area }\left(\mathrm{km}^{2}\right) \text { in } \\
\text { pessimistic } \\
\text { condition }\end{array}$ & $\begin{array}{l}\text { Area }(\%) \text { in } \\
\text { pessimistic } \\
\text { condition }\end{array}$ & $\begin{array}{l}\text { Area in } \\
\text { optimistic } \\
\text { condition }\left(\mathrm{km}^{2}\right)\end{array}$ \\
\hline Low & $0.41-0.51$ & 81.5 & 1.63 & 77.3 & 1.55 & $\begin{array}{l}\text { Area }(\%) \text { in } \\
\text { optimistic } \\
\text { condition }\end{array}$ \\
$\begin{array}{l}\text { Moderately } \\
\text { low }\end{array}$ & $0.51-0.61$ & $1,664.4$ & 33.35 & $1,385.1$ & 27.75 & 103.4 & $1,687.1$ \\
$\begin{array}{l}\text { Moderate } \\
\begin{array}{l}\text { Moderately } \\
\text { high }\end{array}\end{array}$ & $0.61-0.65$ & 879.2 & 17.62 & 361.4 & 7.25 & $1,714.9$ & 34.81 \\
\begin{tabular}{l} 
High \\
\hline
\end{tabular} & $0.65-0.68$ & 880.8 & 17.65 & $1,616.3$ & 32.39 & 37.5 & 1.55 \\
\hline
\end{tabular}


of weights (shown in Table 5) were used to derive the vulnerability indices maps. The characteristics of the vulnerability maps under three different conditions are represented in Table 6 .

The range of the vulnerability indices obtained in most likely condition was reclassified into five classes (low, moderately low, moderate, moderately high, and high) on the basis of Jenks natural breaks that describe the relative probability of contamination of the groundwater resources. Different classes of vulnerability indices and their corresponding ranges are reported in Table 6 . The range of the indices (FPGVI) of five vulnerability classes are: low groundwater vulnerability risk zone $(0.41-0.51)$, moderately low vulnerability risk zone (0.51-0.61), moderate vulnerability zone $(0.61-0.65)$, moderately high vulnerability zone $(0.65-0.68)$, and high vulnerability zone $(0.68-0.84)$. The total area under different vulnerability class and their corresponding percentages are calculated and reported in Table 6 . The results reveal that the percentage of area (total area) under different vulnerability class are $1.63 \%\left(81.5 \mathrm{~km}^{2}\right), 33.35 \%\left(1,664.4 \mathrm{~km}^{2}\right)$, $17.62 \%\left(879.2 \mathrm{~km}^{2}\right), 17.65 \%\left(880.8 \mathrm{~km}^{2}\right)$, and $29.74 \%$ $\left(1,484.1 \mathrm{~km}^{2}\right)$ for low, moderately low, moderate, moderately high and high, respectively. The ranges of the FPGVI in other condition (pessimistic condition and optimistic condition) were reclassified into five classes manually in the same interval, and their corresponding area were calculated and reported in Table 6. Table 6 clearly indicates that the maximum area fall under moderately low class in most likely condition, whereas the maximum area fall under moderately high class and moderate class, respectively in pessimistic and optimistic condition. Thus, the results tell the managers attitude in decision making for waste disposal in the area on the basis of site selection.

\section{Conclusion}

The present study demonstrates the development and application of fuzzy pattern recognition technique for groundwater vulnerability assessment of Ranchi district. The vulnerability indices of Ranchi district were classified into five classes. Both the original DRASTIC method and the proposed fuzzy pattern recognition method were applied to a real-world case study setting, and the results were compared and analyzed. It was shown that by assigning ratings for related parameters falling into a certain range, DRASTIC method may disregard the difference of parameter values within a pre-specified range and is unable to reveal the effect of the variation of the parameters on the vulnerability index. By taking the fuzziness into consideration, the results from the fuzzy method more efficiently reflected the fuzzy nature of the vulnerability index and the effect of the parameters. The evaluation process can be easily programed, so that individuals without geological or hydrological expertise can effectively use the method to evaluate the vulnerability indices of the selected area. This proposed approach not only solves a multi-parameters decision-making problem but also overcomes the information loss seen in classical set theorybased decision making. This approach enables decision makers to evaluate the relative priorities of protecting groundwater, mitigation plan which should be implemented to control on land use activities based on a set of preferences, parameters, and indicators for the area.

Map removal sensitivity analysis confirms the most sensitive to contamination was the parameter, I, followed in importance by parameters $D, C, A, S, T$, and $R$; whereas the single parameter sensitivity analysis results indicate that the new effective weights for each parameter are not equal to the theoretical weights assigned in DRASTIC method. Thus, the computation of effective weights is very useful to revise the weight factors assigned in DRASTIC method and may be applied more scientifically to address the local issues.

Fuzzy-AHP analysis revealed that the vulnerability class may change from one to other depending on the attitudes of the decision makers.

Acknowledgments This research is supported by the University Grants Commission of New Delhi Grant F.N. 39-965/2010 (SR) dated 12.01.2011. Authors are thankful to the editor and reviewers for their valuable suggestions to improve the paper to its best.

\section{References}

Afshar A, Mariño MA, Ebtehaj M, Moosavi J (2007) Rule-based fuzzy system for assessing groundwater vulnerability. J Environ Eng 133(5):532-540

Al-Adamat RAN, Foster IDL, Baban SMJ (2003) Groundwater vulnerability and risk mapping for the Basaltic aquifer of the Azraq basin of Jordan using GIS, remote sensing and DRASTIC. Appl Geogr 23:303-324

Aller L, Bennett T, Lehr JH, Petty RJ (1987) DRASTIC: a standardized system for evaluating groundwater pollution potential using hydrogeologic settings. USEPA, Robert S. Kerr Environmental Research Laboratory, Ada, OK. EPA/600/2 85/0108

Almasri MN (2008) Assessment of intrinsic vulnerability to contamination for Gaza coastal aquifer, Palestine. J Environ Manag 88:577-593

Babiker IS, Mohamed AM, Hiyama T, Kato K (2005) A GIS-based DRASTIC model for assessing aquifer vulnerability in Kakamigahara Heights, Gifu Prefecture, Central Japan. Sci Total Environ 345:127-140

Barber C, Bates LE, Barron R, Allison H (1993) Assessment of the relative vulnerability of groundwater to pollution: a review and background paper for the conference workshop on vulnerability assessment. BMR J Aust Geol Geophys 14(2/3):1147-1154

Burkart MR, Feher J (1996) Regional estimation of groundwater vulnerability to non-point sources of agricultural chemicals. Water Sci Technol 33:241-247

Canter LW (1997) Nitrates in groundwater. CRC Press, Boca Raton, p 263

Carsel RF, Mulkey LA, Lorber MH, Baskin LB (1985) The pesticide root zone model (PRZM): a procedure for evaluating pesticide leaching threats to groundwater. Ecol Model 30:49-69 
Census of India (2011). http://www.census2011.co.in/census/district/ 113-ranchi.html. Accessed Aug 2012

Central Ground Water Board (CGWB) (2011) Groundwater scenario in major cities of India, Ministry of Water Resources. http:// cgwb.gov.in/documents/GW-Senarioin\%20cities-May2011.pdf. Accessed Aug 2012

Chen SY (1994) Theory of fuzzy optimum selection for multi-storage and multi-objective decision making system. J Fuzzy Math 2(1):163-174

Connell LD, Daele G (2003) A quantitative approach to aquifer vulnerability mapping. J Hydrol 276:71-88

Dixon B (2005) Groundwater vulnerability mapping: a GIS and fuzzy rule based integrated tool. Appl Geogr 25:327-347

Eaton AD, Clesceri LS, Greenberg AE (eds) (1995) Standard methods for the examination of water and wastewater, 19th edn. American Public Health Association, Washington

Elçi A (2010) Groundwater vulnerability mapping optimized with groundwater quality data: the Tahtali Basin example, Balwois 2010, water observation and information system for decision support congress Ohrid Republic of Macedonia

Gemitzi A, Petalas C, Tsihrintzis VA, Pissinaras V (2006) Assessment of groundwater vulnerability to pollution: a combination of GIS, fuzzy logic and decision making techniques. Environ Geol 49:653-673

Gogu RC, Dassargues A (2000) Current trends and future challenges in groundwater vulnerability assessment using overlay and index methods. Environ Geol 39:549-559

Hall MD, Shaffer MJ, Waskom RM, Delgado JA (2001) Regional nitrate leaching variability: what makes a difference in northeastern Colorado. J Am Water Resour Assoc 37(1):139-150

Jordan C, Smith RV (2005) Methods to predict the agricultural contribution to catchment nitrate loads: designation of nitrate vulnerable zones in Northern Ireland. J Hydrol 304(1-4):316-329

Korom SF (1992) Natural denitrification in the saturated zone-a review. Water Resour Res 28(6):1657-1668

Lake IR, Lovett AA, Hiscock KM, Betson M, Foley A, Sunnenberg G, Evers S, Fletcher S (2003) Evaluating factors influencing groundwater vulnerability to nitrate pollution: developing the potential of GIS. J Environ Manag 68:315-328

Lee AR (1999) Application of modified fuzzy AHP method to analyse bolting sequence of structural joints, UMI dissertation services. A Bell \& Howell Company

Leonard RA, Knisel WG, Still DA (1987) GLEAMS: groundwater loading effects of agricultural management systems. Trans ASAE 30:1403-1418

Lodwik WA, Monson W, Svoboda L (1990) Attribute error and sensitivity analysis of maps operation in geographical information systems-suitability analysis. Int J Geogr Inf Syst 4:413-428

Mao Y, Zhang X, Wang L (2006) Fuzzy pattern recognition method for assessing groundwater vulnerability to pollution in the Zhangji area. J Zhejiang Univ Sci A 7(11):1917-1922

Margat J (1968) Groundwater vulnerability to contamination. 68, BRGM, Orleans, France. In: Massone et al. (2010). Enhanced groundwater vulnerability assessment in geological homogeneous areas: a case study from the Argentine Pampas. Hydrogeol J 18:371-379

Massone H, Londoño MQ, Martínez D (2010) Enhanced groundwater vulnerability assessment in geological homogeneous areas: a case study from the Argentine Pampas. Hydrogeol J 18:371-379

Merchant JW (1994) GIS-based groundwater pollution hazard assessment- a critical review of the DRASTIC model. Photogramm Eng Remote Sens 60(9):1117-1127

Napolitano P, Fabbri AG (1996) Single parameter sensitivity analysis for aquifer vulnerability assessment using DRASTIC and SINTACS. In: Proceedings of the 2nd HydroGIS conference, IAHS Publication, Wallingford, 235:559-566

Nobre RCM, Rotunno FOC, Mansur WJ, Nobre MMM, Cosenza CAN (2007) Groundwater vulnerability and risk mapping using GIS, modeling and a fuzzy logic tool. J Contam Hydrol 94:277-292
Pal SK, Pal A (2001) Pattern recognition: from classical to modern approaches, World Scientific, Singapore, ISBN No. 981-02-4684-6

Pathak DR, Hiratsuka A (2011) An integrated GIS based fuzzy pattern recognition model to compute groundwater vulnerability index for decision making. J Hydro Environ Res 5:63-77

Pathak DR, Hiratsuka A, Awata I, Chen L (2008) GIS based fuzzy optimization method to groundwater vulnerability evaluation. ICBBE 1011:2716-2719. doi:10.1109/ICBBE.2008

Pathak DR, Hiratsuka A, Awata I, Chen L (2009) Groundwater vulnerability assessment in shallow aquifer of Kathmandu Valley using GIS-based DRASTIC model. Environ Geol 57(7):1569-1578

Qi SL, Gurdak JJ (2006) Percentage of probability of nonpoint source nitrate contamination of recently recharged ground water in the High Plains aquifer: U.S. Geological Survey Data Series. http:// water.usgs.gov/lookup/getspatial?ds192_hp_npctprob. Accessed 14 June 2013

Saaty TL (1977) A scaling method for priorities in hierarchical structures. J Math Psychol 15:234-281

Saaty TL (1980) The analytic hierarchy process: Planning, priority setting and resource allocation. McGraw-Hill, New York

Saaty TL (2000) Fundamentals of decision making and priority theory with the analytic hierarchy process, vol 6, University of Pittsburgh

Saaty TL (2005) Theory and applications of the analytical network process: decision-making with benefits, opportunities, costs, and risk. RWS Publications, University of Pittsburgh, Pittsburgh

Shahid S, Hazarika MK (2007) Geographic information system for the evaluation of groundwater pollution vulnerability of the northwestern Barind tract of Bangladesh. Environ Res J 1(1):27-34

Shirazi SM, Imran HM, Akib S, Yusop Z, Harun ZB (2013) Groundwater vulnerability assessment in the Melaka State of Malaysia using DRASTIC and GIS techniques. Environ Earth Sci 70:2293-2304. doi:10.1007/s12665-013-2360-9

Shouyu C, Guangtao F (2003) A DRASTIC fuzzy pattern recognition methodology for groundwater vulnerability evaluation. Hydrol Sci J 48:211-220

Singh RK, Pawar PS (2012) Comparison of reference evapotranspiratuion estimations across five diverse locations in India. Int $\mathbf{J}$ Appl Innov Eng Manag 1(4):18-27

Thapinta A, Hudak P (2003) Use of geographic information systems for assessing groundwater pollution potential by pesticides in Central Thailand. Environ Int 29:87-93

Thirumalaivasan T, Karmegam M, Venugopal K (2003) AHP-DRASTIC: software for specific aquifer vulnerability assessment using DRASTIC model and GIS. Environ Model Softw 18:645-656

Tim US, Jain D, Liao H (1996) Interactive modeling of ground water vulnerability within a geographic information system environment. Ground Water 34(4):618-627

Tirkey P, Gorai AK, Iqbal J (2013) AHP-GIS based DRASTIC model for groundwater vulnerability to pollution assessment: a case study of Hazaribag District. Int J Env Prot 2(3):20-31

Uricchio VF, Giordano R, Lopez N (2004) A fuzzy knowledge-based decision support system for groundwater pollution risk evaluation. J Environ Manag 73:189-197

Voss CI (1984) SUTRA: a finite element simulation model for saturated-unsaturated, fluid-density dependent ground-water flow with energy transport or chemically reactive single species solute transport. US Geological Survey, National Centre, Reston VA

Wagenet RJ, Histon JL (1987) Predicting the fate of nonvolatile pesticides in the unsaturated zone. J Environ Qual 15:315-322

Zadeh LA (1965) Fuzzy sets. Inform Control 8:338-353

Zahedi F (1986) Group consensus function estimation when preferences uncertain. Oper Res 34(6):883-894

Zhou H, Wang G, Yang Q (1999) A multi-objective fuzzy pattern recognition model for assessing groundwater vulnerability based on the DRASTIC system. Hydrol Sci J 44(4):611-618 